\title{
LA DESCONFIANZA DE LOS JÓVENES: SUSTRATO DEL MALESTAR SOCIAL
}

\author{
MARIO SANDOVAL
}

\begin{abstract}
RESUMEN
La hipótesis central que se desarrolla en este artículo es que la desconfianza de los jóvenes en los demás -y especialmente la desconfianza en las instituciones- es el sustrato del malestar social que se ha expresado en el último tiempo en las calles de Chile y más allá de las fronteras nacionales. Dicho malestar se está articulando en un movimiento juvenil internacional denominado los «indignados». Para el presente artículo se trabaja con los resultados parciales de la investigación «Vinculaciones entre la construcción y deconstrucción de la confianza y la cohesión social en jóvenes estudiantes de educación secundaria: lineamientos para fortalecer la democracia» financiada por Fondecyt.
\end{abstract}

PALABRAS CLAVE: CONFIANZA, JÓVENES, DEMOCRACIA

* Doctor en Sociología de la Universidad Católica de Lovaina (UCL) y Post-Doctor en Sociología de la Juventud y la Educación de la UCL. Actualmente es Coordinador del «Centro de Estudios en Juventud» (CEJU), Universidad Católica Silva Henríquez. E-Mail: msandoval@ucsh.cl. El presente artículo es fruto del Proyecto Fondecyt N¹100649 «Vinculaciones entre la construcción y deconstrucción de la confianza y la cohesión social en jóvenes estudiantes de educación secundaria: lineamientos para fortalecer la democracia». 


\title{
A DESCONFIANÇA DOS JOVENS: \\ SUBSTRATO DO MAL-ESTAR SOCIAL
}

\begin{abstract}
RESUMO
A hipótese central desenvolvida neste artigo é que a desconfiança dos jovens em relação aos outros —e especialmente a desconfiança nas instituições — é o substrato do mal-estar social manifestado nos últimos tempos nas ruas do Chile e para além das fronteiras nacionais. Este mal-estar está se articulando em um movimento juvenil internacional denominado os «indignados». Para o presente artigo, trabalha-se com os resultados parciais da pesquisa «Vinculações entre a construção e desconstrução da confiança e a coesão social em jovens estudantes de educação secundária: diretrizes para fortalecer a democracia», financiada por Fondecyt.
\end{abstract}

PALAVRAS CHAVE: CONFIANÇA, JOVENS, DEMOCRACIA

\section{DISTRUST IN YOUNG PEOPLE: SUBSTRATE OF SOCIAL DISTRESS}

\begin{abstract}
The central hypothesis developed in this article is that the distrust of young people in others, and especially distrust of institutions, is the bedrock of social unrest that has been expressed in recent times on the streets of Chile and beyond national borders. Such discomfort is being articulated in an international youth movement called the «outraged». This article works with the partial results of the investigation «linkages between construction and deconstruction of social cohesion and confidence in young students in secondary education: guidelines for strengthening democracy», funded by Fondecyt.
\end{abstract}

KEY WORDS: TRUST, YOUTH, DEMOCRACY 


\section{PREsentación}

PARA COMPRENDER EL PRESENTE juvenil chileno, es imprescindible referirse, aunque sea someramente, a la historia reciente, historia compleja, a veces sorprendente, inquietante para algunos y estimulante para otros.

La hipótesis que sustenta este planteamiento es que resulta imposible comprender la realidad juvenil actual si no conocemos el contexto en el cual esta realidad se está verificando, en otros términos, la juventud es una construcción social. Por lo tanto, la manera cómo los jóvenes vivan su juventud dependerá de las coordenadas socio/político/cultural/históricas/económicas y religiosas; muchas personas podrán ser jóvenes, pero no viven su juventud, como se supone que deberían vivirla.

Cada contexto posibilita, favorece, dificulta o impide que los jóvenes vivan su juventud. Es decir, vivir la juventud no depende únicamente de la condición etaria; se requieren otras condiciones socioambientales para poder vivir la moratoria y prepararse adecuadamente para entrar al mundo adulto con los capitales necesarios y suficientes como para ser un adulto exitoso, integrado, adaptado (entre otras cualidades).

La juventud tal cual la concebimos hoy día es un fenómeno moderno, solo a partir de la aparición de la Escuela, como institución especializada en la educación, comienza a considerarse una determinada etapa de la vida como juventud, entendida como constructo sociológico. Sin embargo, para realizar un estudio en profundidad del fenómeno juvenil es imprescindible dar cuenta de ello desde una perspectiva histórica, de tal manera de comprender que la presencia de los jóvenes en las distintas sociedades ha sido relevante.

Otro aspecto necesario de considerar es la posibilidad de convertirse en actor social, en ser protagonista de la historia, de los cambios sociales y políticos ocurridos en el país; en este sentido, si uno visualiza distintos procesos sociopolíticos a nivel mundial se puede constatar que en cada uno de ellos los jóvenes de esas épocas jugaron un rol fundamental en el quehacer de esas sociedades; es decir, es necesario analizar el fenómeno desde una perspectiva diacrónica. Por lo tanto, se trata de comprender lo que hacen los jóvenes y cómo lo hacen a la luz de la historia.

Es un error pensar que solo actualmente los jóvenes están protagonizando una cierta actoría social; afirmarlo es desconocer la historia y no comprender la continuidad en los comportamientos juveniles de 
todas las épocas, ligados a su contexto cultural, económico y político por supuesto. Es por ello que es necesario contextualizar sus conductas individuales y colectivas en el periodo analizado. Sin embargo y, a pesar de lo dicho anteriormente, está por verse si ese protagonismo se mantiene en el tiempo y logra promover los cambios que propugna.

Dada las limitaciones de espacio, nos referiremos, en orden cronológico, solo a algunos hechos protagonizados por jóvenes, todos los cuales dan cuenta de la participación juvenil en diferentes procesos de cambio sociopolítico.

\section{LOS JÓVENES EN EL MUNDO}

Como todos sabemos, el 1 de enero de 1959 triunfó la revolución cubana comandada por los llamados «barbudos de la sierra maestra», todos jóvenes menores de 30 años. Es decir, la revolución cubana fue un proceso político militar de gran envergadura que fue liderado íntegramente por jóvenes. Si bien las acciones guerrilleras culminaron el día del año nuevo de 1959, éstas se habían iniciado mucho antes. Cabe destacar que anteriormente, el 26 de julio de 1953 un grupo de 135 guerrilleros opositores a la Dictadura de Fulgencio Batista, liderados por Fidel Castro, Raúl Castro y Abel Santamaría asaltaron el Cuartel Moncada. A esa fecha, Fidel Castro tenía 27 años, Raúl Castro tenía 22 y Abel Santamaría, 26 años. Ese acto — que fracasó militarmentefue el comienzo de la lucha revolucionaria que culminaría el $1^{\circ}$ de enero de 1959.

Posteriormente, en 1956 un grupo de 82 jóvenes revolucionarios encabezados por Fidel Castro y Ernesto «Che», Guevara, junto a Raúl Castro, Camilo Cienfuegos, Ramiro Valdés y Juan Almeida (entre otros) organizaron una expedición desde México con el fin de ingresar clandestinamente a Cuba para dar inicio a la llamada «revolución cubana»; desembarcaron en Cayuelos, cerca de la playa Las Coloradas a bordo del barco el Granma; en esa fecha Fidel Castro tenía 30 años, el Che Guevara 28 años, Raúl Castro 25 años, Camilo Cienfuegos 24 años, Ramiro Valdés 24 años y Juan Almeida 29.

Otro ejemplo lo encontramos en Francia; es el caso del «mayo francés». Nos referimos a Mayo de 1968, cuando miles de estudiantes franceses salieron a las calles a protestar, motivados inicialmente por el deseo de compartir habitaciones entre hombres y mujeres en las viviendas universitarias. Sin embargo, a partir de ese hecho puntual se cuestionó todo el sistema universitario y por extensión el sistema polí- 
tico de la época. Lo que importa destacar es que fueron los jóvenes los que protagonizaron uno de los procesos de cambio social más importante de la Francia contemporánea.

Fueron los estudiantes de sociología de la Universidad de Nanterre, ubicada en las afueras de París, los primeros y principales activistas del movimiento. Daniel Cohn Bendit, su principal líder tenía 23 años. Ellos consideraban que la Universidad tenía que convertirse en el centro de una revolución contra el capitalismo imperante en Francia en esa época. Con ese fin, en abril de 1968 se tomaron el campus de la Universidad y las autoridades lo clausuraron; como consecuencia los estudiantes de Nanterre se trasladaron a París y ocuparon la histórica Universidad de La Sorbona, ante lo cual las autoridades universitarias solicitaron la intervención de la policía para su desalojo, violando de esta manera la histórica autonomía universitaria. Este hecho causó la indignación del pueblo francés y de los estudiantes, los que junto a los sindicatos de académicos llamaron a una huelga general a la cual se sumaron más de nueve millones de trabajadores, generando la sorpresa del Presidente, General Charles De Gaulle y de su Ministro del Interior Georges Pompidou, quienes se encontraban fuera del país.

Lo interesante y novedoso de los hechos ocurridos en Francia está relacionado con las motivaciones de los jóvenes protagonistas; esas motivaciones tenían que ver con el deseo de cambiar la forma de vivir en ese país y en este mundo, hacer una sociedad de personas libres y plenamente desarrolladas, una utopía que por primera vez alcanzó el estatus de movimiento social. Los discursos y las demandas estudiantiles hablaban de Vietnam, de la universidad, del antiimperialismo, y se plasmaron simbólicamente en los miles de grafitis que han pasado a la historia y que forman parte de la herencia cultural del Mayo francés:

Viva la comunicación, abajo la telecomunicación.

Dios: sospecho que eres un intelectual de izquierda.

La barricada cierra la calle, pero abre el camino.

Camaradas: proscribamos los aplausos, el espectáculo está en todas partes.

Tomemos en serio la revolución, pero no nos tomemos en serio a nosotros mismos.

No es una revolución, majestad, es una mutación.

Prohibido prohibir. La libertad comienza por una prohibición.

La emancipación del hombre será total o no será.

Queremos las estructuras al servicio del hombre y no al hombre al servicio de las estructuras.

Un policía duerme en cada uno de nosotros, es necesario matarlo. 
Abraza a tu amor sin dejar tu fusil.

Las jóvenes rojas cada vez más hermosas.

La imaginación toma el poder.

Olvídense de todo lo que han aprendido, comiencen a soñar.

Sean realistas: pidan lo imposible.

Cuanto más hago el amor, más ganas tengo de hacer la revolución.

Cuanto más hago la revolución, más ganas tengo de hacer el amor.

Ese mismo año, pero en México, sucedieron los hechos de la Plaza Tlatelolco (también conocida como Plaza de las Tres Culturas), precisamente el 2 de octubre de 1968. A diez días del inicio de los Juegos Olímpicos, el gobierno de Gustavo Díaz Ordaz reprimió una revuelta estudiantil, deteniendo a más de 6.000 jóvenes y asesinando entre trescientos y quinientos. Esa masacre estuvo precedida por varios meses de inestabilidad política en Ciudad de México, con manifestaciones y protestas estudiantiles que tenían como objetivo apoyar los hechos que sucedían en el mundo, especialmente lo que había ocurrido en mayo en París.

El 27 de agosto de ese mismo año, más de 200.000 estudiantes marcharon por el centro de Ciudad de México y se instalaron en el Zócalo; al día siguiente fueron reprimidos por la policía y el ejército mexicanos. Los jóvenes estudiantes querían atraer la atención que había sobre la ciudad a raíz de los Juegos Olímpicos de 1968.

El Presidente de la época, Gustavo Díaz Ordaz, estaba empeñado en detener las protestas y unas semanas antes de la masacre de la Plaza Tlatelolco, ordenó al ejército ocupar el campus de la Universidad Nacional Autónoma de México (UNAM). El ejército detuvo y golpeó indiscriminadamente a muchos estudiantes y como señal de protesta el Rector Javier Barros Sierra renunció a su cargo.

Las protestas juveniles aumentaron y el 2 de octubre, luego de nueve semanas de huelga estudiantil, 15.000 estudiantes de varias universidades marcharon por las calles de la ciudad, llevando claveles rojos para protestar por la ocupación del campus universitario de la UNAM. En la noche 5.000 estudiantes y trabajadores se congregaron en la Plaza de las Tres Culturas en Tlatelolco y el ejército con carros blindados y tanques de guerra rodearon la plaza y abrieron fuego, apuntando a las personas que protestaban y a las que pasaban por el lugar. La masacre continuó durante la noche, los soldados allanaron los edificios adyacentes a la plaza y testigos de los hechos aseguran que los cuerpos fueron sacados de la plaza en camiones de basura. Hasta el día de hoy los gobiernos mexicanos cargan el oprobio de 
nunca haber castigado a los militares responsables de la represión y muerte de cientos de jóvenes estudiantes mexicanos.

$\mathrm{Al}$ año siguiente se produjo el «Cordobazo» en Argentina. El 29 de mayo de 1969, obreros y estudiantes cordobeses y de otras provincias salieron a las calles de la provincia de Córdoba para protestar contra el Gobierno de turno. Dada la magnitud de la movilización social, el Presidente Onganía ordenó que las Fuerzas Armadas se hicieran cargo de la represión, dejando decenas de heridos y dieciséis muertos. La consecuencia de esta represión contra los jóvenes cordobeses fue que las protestas se extendieron a otras provincias. Rosario fue declarada zona de emergencia y colocada bajo jurisdicción militar y en Tucumán se profundizaron los conflictos y protestas juveniles. El «Cordobazo» fue el inicio de un proceso de agudización de las protestas sociales y la lucha armada que se desarrolló por varios años en Argentina.

Una característica importante del movimiento estudiantil de 1969 en Argentina fue la crítica a la organización, los contenidos y las prácticas educativas. Acción estudiantil que se inscribía en una continuidad de la reforma educacional de 1918, centrando su preocupación y demanda por la calidad de la educación, al igual que los estudiantes chilenos en la actualidad, con cuarenta años de diferencia.

Lo interesante de lo realizado por los estudiantes argentinos en 1969 fue la radicalización de sus planteamientos y el inicio de la acción directa en muchas Escuelas y Universidades. Esta acción directa se focalizaba contra los académicos quienes eran considerados los representantes del statu quo o los ejecutores de una política de dictadura académica; que se manifestaba, según ellos, en mala calidad de sus conocimientos, desactualización curricular, falta de pluralismo en los discursos, autoritarismo en la relación profesor-alumno.

Por otra parte, en 1979 tuvo lugar el triunfo de la revolución nicaragüense encabezada por el Frente Sandinista de Liberación Nacional, formado mayoritariamente por jóvenes, no por nada se le llamó «la revolución de los muchachos», debido a que una gran cantidad de ellos eran menores de edad. Nicaragua y sus habitantes estuvieron sometidos por más de cincuenta años bajo la dinastía de los Somoza y su ejército privado, la Guardia Nacional. Esta situación de miseria, exclusión y opresión hizo surgir en 1961 un movimiento militar que pretendía derrocar por la fuerza a la dictadura somocista. El movimiento tomó el nombre de César Augusto Sandino. Es así como nació el Frente Sandinista de Liberación Nacional (FSLN), fundado por un grupo de jóvenes liderados por Carlos Fonseca de 26 años, Samuel 
Santos de 23 años, Tomás Borge tenía 31, Germán Pomares, 24 y Silvio Mayorga, 23 años.

Más tarde, el 19 de julio de 1979, miles de jóvenes guerrilleros y civiles entraron a la Plaza de la República, en el antiguo centro de Managua, celebrando el triunfo de la revolución nicaragüense y la caída definitiva de la dictadura dinástica de los Somoza. Un dato que impacta es que al momento del triunfo de los sandinistas: el 53\% de la población era analfabeta. Uno de los principales líderes del proceso revolucionario, Daniel Ortega (actual Presidente de Nicaragua) a la fecha tenía 34 años.

En 1989, en la República Popular China entre el 15 de abril y el 4 de junio sucedieron los hechos de la Plaza Tiananmen protagonizados por miles de jóvenes. Ellos comenzaron a protestar porque consideraban que el gobierno del Partido Comunista era demasiado represivo y corrupto, que la inflación y el desempleo estaban amenazando sus formas de vida. El acontecimiento que inició las protestas fue el asesinato del joven $\mathrm{Hu}$ Yaobang, de esta manera comenzaron a desarrollarse las manifestaciones en la plaza, las que fueron brutalmente reprimidas por el Ejército Popular de Liberación, dando paso a lo que se conoce en la República Popular China como «la masacre de la Plaza Tiananmen».

En cuarenta años de régimen comunista nunca se había producido una protesta tan masiva. Cuando los manifestantes llegaron a un millón de personas, el gobierno empezó a reprimir a los estudiantes, es así como el 20 de mayo de 1989, el Gobierno declaró la ley marcial y en la noche del 3 de junio envió los tanques y la infantería del ejército a la plaza de Tiananmen para disolver las protestas, matando a cientos o miles de jóvenes: nunca se va a saber la cifra exacta. El gobierno chino nunca difundió las cifras oficiales de muertos. Diversos organismos —entre ellos la Cruz Roja China- hablaron de entre 400 y 2.600 jóvenes. La mayoría de los estudiantes fueron asesinados en las calles aledañas, alcanzados por las balas policiales y militares mientras escapaban. Los heridos se estimaron entre 7.000 y 10.000 aproximadamente. Luego de la violenta represión, el Gobierno detuvo a cientos de jóvenes considerados los líderes del movimiento, expulsó a la prensa extranjera y controló estrictamente la cobertura de los acontecimientos en la prensa china.

Sin lugar a dudas, el hecho sociopolítico más trascendental del siglo XX fue la destrucción del Muro de Berlín, más conocido como la «caída» del Muro de Berlín. Dicho concepto nos parece equívoco e inexacto, dado que tiene la connotación de un hecho fortuito, acciden- 
tal; es como si el Muro se hubiera caído por un terremoto; claro que hubo un «terremoto», pero éste fue un «terremoto juvenil», porque fueron los jóvenes de Europa del Este quienes destruyeron el Muro, cambiando el curso de la historia.

El Muro de Berlín se empezó a construir el 13 de agosto de 1961 y separó físicamente a la entonces llamada República Federal Alemana (RFA) de la República Democrática Alemana (RDA). La Alemania del Este lo denominaba «Muro de Protección Antifascista» (Antifaschistischer Schutzwall) y desde el lado occidental lo apodaban el «Muro de la Vergüenza» (Schandmauer). El Muro tenía una extensión de cuarenta y cinco kilómetros, dividía a la ciudad de Berlín en dos y 115 kilómetros separaban a la parte occidental de la ciudad del territorio de la RDA. Este fue uno de los símbolos más conocidos de la llamada Guerra Fría.

Pero más allá de los aspectos físicos y materiales de la construcción, simbólicamente el Muro separaba dos mundos, dos modelos de desarrollo; por un lado, el modelo de desarrollo capitalista, representado por la RFA y por el otro, el modelo de desarrollo socialista, representado por la RDA. Con el tiempo esta situación se hizo insostenible y los jóvenes pertenecientes a diversos países de Europa del Este comenzaron a protestar por las restricciones que se les imponían, sobre todo a su libertad de desplazamiento. Valga como ejemplo que en septiembre de ese año más de 13.000 jóvenes alemanes orientales emigraron hacia Hungría. Dada esta situación las protestas y manifestaciones juveniles se masificaron y en particular en la RDA hacia fines de 1989 se multiplicaron las protestas contra el presidente Erich Honecker, quien renunció el 18 de octubre.

Todos estos hechos culminaron la noche del jueves 9 de noviembre de 1989, fecha en que definitivamente se abre la frontera entre las dos Alemanias y aún se mantiene en la retina mundial la imagen de miles de jóvenes europeos sobre el Muro, premunidos de picotas y chuzos, derribando el Muro y poniendo fin a una época.

La historia juvenil continúa y es así como el año 2011 fuimos testigos de los hechos ocurridos en España, Bélgica e Inglaterra, entre otros países europeos. En todos ellos se están manifestando miles de jóvenes contra lo que consideran la opresión del capitalismo, contra las desigualdades y contra el imperio de los bancos y entidades financieras internacionales. Por su parte, en el norte de África también miles de jóvenes han salido a las calles a protestar contra regímenes autoritarios y déspotas, que gobiernan desde hace décadas y que mantie- 
nen a sus pueblos en la miseria, la ignorancia y la exclusión, en lo que se ha llamado «la primavera árabe». En todos esos casos están siendo nuevamente los jóvenes los que salen a la calle a protestar y a exigir cambios radicales al sistema imperante, es el Movimiento conocido como «los indignados».

Este Movimiento debe su nombre a Stéphane Hessel (2010), autor del libro «Indignez-Vous» (Indígnense). En su pequeño libro — de sólo treinta y dos páginas- Hessel invita a los jóvenes a revivir «la herencia y los ideales de la Resistencia», y los conmina a encontrar algo que los inspire y que manifiesten su indignación, como lo hicieron los jóvenes franceses durante la ocupación nazi. Hessel plantea la indignación como «una cualidad esencial del hombre» y como una obligación sociopolítica contra el bienestar de los ricos y el imperio de las finanzas.

Los «indignados» se hicieron visibles a la opinión pública mundial el 15 de mayo de 2011 a través de una serie de protestas pacíficas en España con la intención de promover una democracia más participativa, alejada del bipartidismo PSOE/PP y del dominio de bancos y corporaciones financiera internacionales, abogando por una «auténtica división de poderes» y otras medidas con la intención de mejorar el sistema democrático. Ese domingo de mayo había elecciones municipales en España y los jóvenes llamaron a abstenerse de votar acampando en las plazas, siendo la Plaza del Sol de Madrid el epicentro de las manifestaciones juveniles.

Así como los jóvenes del mayo francés del 68 inventaron sus famosos grafitis, estos jóvenes «indignados» con el poder, con la riqueza, con los abusos y las exclusiones, también crearon sus consignas, tales como: «no somos marionetas en manos de políticos y banqueros» 0 «democracia real ; YA!».

Los principios del movimiento juvenil de los indignados son el apartidismo - es decir, no reconocen ninguna afiliación a partidos políticos o sindicatos-, el pacifismo, la horizontalidad y la transparencia. Se organizan a través de asambleas populares abiertas, celebradas en plazas o parques y está estructurado en diversas comisiones (Legal, Comunicación, Acción, Actividades, Barrios, Estatal e Internacional, Información, Infraestructuras, Lenguas de Signos) y grupos de trabajo (Cultura, Educación, Política, Economía, Medio Ambiente, Trabajo Social, Feminismos, Ciencia y Tecnología, Diálogo entre Religiones, Migración y Movilidad, Pensamiento).

Luego de los hechos ocurridos el 15 de mayo en la Puerta del Sol de Madrid, el movimiento comenzó a extenderse a otras ciudades eu- 
ropeas, asiáticas, africanas y americanas, realizándose movilizaciones y manifestaciones juveniles de protesta en Praga, Londres, Ámsterdam, París, Bruselas, Jerusalén, Budapest, Varsovia, Viena, Berlín, Lisboa, Atenas, Nueva York, Tánger y Rabat, entre otras. Todos ellos manifiestan que «el sistema no funciona. Tenemos que cambiarlo por otro mejor que nos represente a todos», «estamos hartos» y «no aguantamos más» e identifican como culpables de la situación a los políticos corruptos, a los bancos y entidades financieras internacionales.

\section{LOS JÓVENES EN CHILE}

En Chile, ya en la década del 60 se generó un «paradigma» de juventud, es decir un modelo que fue imitado por el resto de la población juvenil. Ese paradigma era el de «joven revolucionario», que correspondía en rigor a una minoría de la juventud chilena de la época, eran los jóvenes universitarios, de clase media y politizados, sin embargo, a partir de ese paradigma se hablaba de la «juventud chilena».

Fue una época en que la política llenó los imaginarios juveniles y les permitió articular proyectos de vida en función del cambio social; no solo en Chile, sino que en muchos países de América Latina los jóvenes fueron protagonistas de sendos procesos de cambios sociales y políticos pacíficos y en algunos casos muy violentos.

Durante la dictadura militar chilena (1973-1989) fueron los jóvenes pobladores quienes salieron a las calles a protestar y generaron las bases de sustentación de las negociaciones políticas posteriores que permitieron una salida democrática a la dictadura, sin embargo, la «deuda social» de la cual ellos son acreedores nunca fue pagada. Esos jóvenes de la época hoy tienen más de cincuenta años.

Es por eso que no es de extrañar que en la actual coyuntura nacional sean precisamente los jóvenes quienes nuevamente salgan a las calles a demandar educación de calidad, cambios a la Constitución Política del Estado, educación gratuita, fin al sistema binominal, renacionalización del cobre (entre otras). En síntesis, los jóvenes estudiantes (secundarios y universitarios) están catalizando las demandas ciudadanas por una sociedad más justa e igualitaria, al igual que los jóvenes indignados del resto del mundo.

Para nadie son desconocidas las inmensas desigualdades que ha generado el modelo económico neoliberal imperante en Chile desde inicios de la dictadura, modelo que se mantuvo sin mayores variaciones durante los gobiernos de la Concertación de Partidos por la Democracia. 
Dicho modelo ha generado una inmensa concentración de la riqueza y las mayores desigualdades internas que se hayan visto en la historia de Chile; dichas desigualdades se manifiestan en enormes deudas económicas de todo tipo, entre ellas, las deudas de las familias con los bancos, deudas relacionadas con el pago de los aranceles universitarios.

Ya en el año 2006 la llamada «revolución de los pingüinos» expresó públicamente el descontento juvenil, sin embargo, la cooptación de la que fueron objeto no permitió ningún cambio ni mejora sustancial en la calidad de la educación.

Dichas demandas han vuelto a las calles con mayores bríos y son, nuevamente, los jóvenes quienes se manifiestan, ellos tiene la energía, la claridad y la valentía de decir en voz alta: «basta de abusos», «basta de desigualdades». Son los estudiantes quienes catalizan el descontento ciudadano, son los que demuestran el hastío, la indignación y la desconfianza con los poderes instituidos.

\section{a) La confianza desde los jóvenes}

Pero, ¿qué existe a la base de este malestar ciudadano juvenil chileno? La hipótesis central de este artículo es que la desconfianza es el sustrato de este malestar social, por lo tanto, es necesario definir qué es la confianza para los jóvenes.

Más allá de las muchas definiciones conceptuales que existen, nos interesa capturar la visión de los jóvenes acerca de la confianza; es decir, ¿qué es la confianza para ellos? Es por eso que a continuación vamos a presentar un conjunto de definiciones juveniles de confianza y datos sobre confianza que hemos recogido a través de nuestro estudio «Vinculaciones entre la construcción y deconstrucción de la confianza y la cohesión social en jóvenes estudiantes de educación secundaria: lineamientos para fortalecer la democracia», financiada por Fondecyt.

Confianza es «creer en alguien o en algo y entregarse por entero» nos señaló uno de los jóvenes entrevistados. En esta definición juvenil subyace todo un sustrato valórico. Los jóvenes valoran la autenticidad, la sinceridad, la lealtad, la coherencia, el compromiso con el otro. Esos valores son vistos y apreciados por los jóvenes y es justamente (al decir de ellos), «lo que los aleja del mundo adulto». Ellos ven en el mundo institucional, y adulto en general, un doble estándar: «dicen una cosa y se hace otra», «se promete y no se cumple» (sobre todo los políticos); por eso que no confían en las instituciones y toman distancia de ellas. 
Muchos de nuestros entrevistados nos señalaron que la confianza se mide en «la capacidad del otro de guardar un secreto» y eso es «verdadera amistad». Cuando un amigo confía en otro y le cuenta un secreto, la expectativa natural es que el otro guarde el secreto como lo más preciado, sin traicionar la confianza depositada en él o ella. Eso es para los jóvenes un indicador claro de una verdadera amistad, eso es la confianza.

Para poder confiar en otros es imprescindible «confiar en uno mismo»; confiar en lo que somos, tal cual la naturaleza nos ha creado, con nuestras características físicas y psicológicas; con nuestras capacidades, virtudes y defectos. «Confiar en uno mismo nos permite actuar con seguridad frente a los demás» nos señaló una joven entrevistada. Tener confianza en uno mismo significa «tener fe en lo que somos», por lo tanto, no necesitamos aparentar nada, ni fingir situaciones de las que no somos parte. Lo anterior implica autenticidad y sinceridad en las relaciones interpersonales, facilitando la amistad profunda.

Contrariamente, la desconfianza entre las personas afecta negativamente el funcionamiento del país, sin embargo, el sentir juvenil nos indica que es mucho más grave «no confiar en las personas, que no confiar en las instituciones», lo anterior refleja un sustrato ético fundamental en las interacciones juveniles. Los jóvenes valoran sobre todo su círculo más cercano, su familia, sus amigos, su pareja, sus profesores (no la escuela). En ellos se deposita la confianza, como una certidumbre básica de la vida cotidiana, sin la cual no podríamos vivir.

Las investigaciones realizadas a nivel nacional (INJUV, 2009; PNUD, 2009) demuestran que los jóvenes valoran enormemente la sinceridad, la coherencia y la honestidad en las relaciones personales, todos esos son valores que están a la base de la confianza. Sin embargo, la postura juvenil frente al mundo institucional es de distancia, de desimplicación, de rechazo, por lo tanto, a ellos les parece mucho más grave «no confiar en los amigos», que no confiar en la escuela, en las municipalidades o en el gobierno central.

Hasta ahora, uno de los indicadores clásicos de esta distancia y desconfianza de los jóvenes hacia el mundo institucional está reflejado en las bajas cifras de inscripción y participación electoral. Según los datos del Servicio Electoral (SERVEL, 2012), en el Plebiscito de 1988 la participación electoral de los jóvenes entre 18-19 años fue de un $5,11 \%$ (porcentaje respecto del total del padrón electoral), de 20-24 años fue de $15,14 \%$ y de $25-29$ fue de $14,52 \%$, con un promedio de participación electoral juvenil para el rango 18-29 años de un 11,59\%. 
Mientras que en las últimas elecciones presidenciales y parlamentarias realizadas en el país el año 2009 las cifras fueron aun peores. La participación para el tramo etario de 18-19 años fue de un 1,06\%; de 2024 años fue de un 3,40\% y para el tramo etario de 25-29 años fue de un $4,32 \%$, con un promedio de participación electoral juvenil para el rango $18-29$ años de un 2,92\%. Es decir, queda en evidencia que la participación electoral juvenil bajó de 11,59\%, en 1988 a 2,92\% en el 2009, eso significa un $8,67 \%$ puntos porcentuales menos. Entre otras cosas, lo anterior significa que el peso electoral de los jóvenes en Chile es ínfimo.

El padrón electoral actual (SERVEL, 2012) asciende a 8.110.265 inscritos mayores de 18 años, de éstos, el tramo etario de 18-19 años solo representa el $0,56 \%$, (45.417 jóvenes), el tramo siguiente de 20 24 años representa el 2,92\% (236.819 jóvenes) y finalmente el tramo de 25-29 años representa el 4,57\% (370.639 jóvenes). Si consideramos los tres tramos en su conjunto, el peso de los jóvenes en el padrón electoral alcanza apenas a un 2,68\%.

Esta bajísima inscripción se va a revertir con la puesta en vigencia de la ley de Inscripción automática y voto voluntario. Los cálculos electorales señalan que con esta nueva ley (pronta a entrar en vigencia) el universo electoral aumentará considerablemente. Sin embargo, nada asegura que votarán más ciudadanos; al ser el voto voluntario es perfectamente posible suponer que muchos electores adultos dejen de votar y que los jóvenes mantengan su abstención electoral como una manifestación de rechazo al mundo político; todo ello está por verse.

Otro de los aspectos enfatizados por los jóvenes es que «la confianza se construye, es un proceso; no surge espontáneamente»; por lo tanto, hay que hacerse merecedor de la confianza y cuidar las relaciones interpersonales para mantenerla.

\section{b) El descontento y la incertidumbre juvenil}

Pareciera haber consenso entre distintos autores en señalar que la época presente es de incertidumbre, líquida, transparente, de riesgo, evanescente, vacía; época transicional que corroe el carácter y se manifiesta, entre otros indicadores, en la falta de respeto de los jóvenes hacia los adultos (Lipovetsky, 1983; Giddens, 1994; Bajoit, 1996; Fukuyama, 1996; Brunner, 1998; Vattimo, 1998; Beck, 2003 y 2008; Morin, 2005; Bauman, 2006; Zennet, 2006; Touraine, 2006; Hopenhayn, 2007; Maffesoli, 2007; Martuccelli, 2007; Sader, 2009). 
El modelo económico imperante en Chile ha tenido un fuerte desgaste en los últimos años. Las promesas de integración (vía mercado) no cumplidas han facilitado la conjunción de intereses y objetivos comunes entre los jóvenes, visibilizándolos al conjunto de la sociedad chilena en una versión criolla de «los indignados». Lo que resta por saber es si esa conjunción de intereses permanecerá en el tiempo o solo será - al igual que el año 2006 - una coyuntura pasajera.

Existen muchos motivos para que los jóvenes chilenos estén indignados: motivos políticos, económicos, culturales, sociales, religiosos y familiares. Pareciera que nada es como los jóvenes quisieran que fuera; en cada una de las acciones colectivas desplegadas por los estudiantes secundarios y universitarios se está manifestando el descontento, la indignación, la falta de confianza en las instituciones, la falta de credibilidad en una democracia que no satisface sus demandas; demandas que trascienden el ámbito educativo.

Este descontento generalizado se ha instalado en la subjetividad juvenil, pero tiene fuentes objetivas muy claras y contundentes; es así como la Encuesta Latinobarómetro (2011) señala que solo el 6\% de los chilenos considera que la distribución del ingreso en Chile es justa (período 1997-2011), en contraste con países como Ecuador y Panamá, donde un $43 \%$ y $33 \%$ respectivamente consideran que la distribución de los ingresos en sus países es justa. Al mismo tiempo la misma Encuesta señala que el 55\% de los encuestados (período 2010-2011) considera que el país está gobernado por un grupo de poderosos que trabajan por su propio beneficio.

Complementariamente, el $84 \%$ de los encuestados considera que el crecimiento del país no se refleja en su situación personal (Encuesta Metropolitana del Centro de Investigación en Estructura Social - CIES-, Universidad de Chile, 2009), mientras que los resultados del estudio «Epidemiología del suicidio en la adolescencia y juventud»—realizado por María Inés Romero, médica pediatra e investigadora del Departamento de Salud Pública de la Facultad de Medicina de la Universidad Católica- demuestran que la tasa de suicidios juveniles se duplicó en los últimos veinte años y el consumo de antidepresivos aumentó en un 470,2\% entre 1990 y 2004 (Jirón, 2008).

Todos estos datos nos permiten afirmar que la sociedad chilena ha sido «portadora y reproductora de un enorme malestar subjetivo, más bien vago y desestructurado en su forma, pero que su fondo está íntimamente relacionado con variables objetivas a las cuales se ha desatendido» (Mayol, 2011). 
Al comparar a Chile con otros países, en relación a los niveles de confianza en las personas, podemos concluir que Chile es el país de los desconfiados.

\section{CUADRO 1: LA CONFIANZA EN LOS DEMÁS EN COMPARACIÓN CON CHILE}

\begin{tabular}{|c|c|}
\hline Suecia & $66 \%$ \\
\hline Holanda & $53 \%$ \\
\hline Alemania & $38 \%$ \\
\hline España & $36 \%$ \\
\hline Chile & $14 \%$ \\
\hline
\end{tabular}

FUENTE: PNUD, 2009.

A través de la investigación que hemos realizado en tres regiones del país (Metropolitana, Quinta y Octava) con estudiantes secundarios hemos podido corroborar estos datos generales desde la subjetividad juvenil, vehiculizada en sus relatos. Es así como ellos señalan que en la sociedad chilena actual «cada uno vela por sí mismo», lo cual genera un enorme individualismo y desconfianza en los demás, que la tendencia generalizada en el mundo juvenil es a intentar «integrarse a la sociedad a través del consumo», constituyendo una sociedad de consumidores y clientes. Al respecto, cabe preguntarse en qué y cómo se manifiesta actualmente la «ciudadanía juvenil».

La falta de confianza en los otros y en las instituciones no permite la generación de proyectos colectivos y atenta directamente contra la cohesión de la sociedad chilena, por lo tanto, hay una dificultad endémica de articular cambios sociopolíticos profundos (colectivos), considerando que los jóvenes no tienen poder, solo legitimidad, es por eso que las manifestaciones de protesta juvenil del 2011 plantean la tensión entre la búsqueda de soluciones personales a los problemas que los aquejan (tendencia de largo plazo) versus la búsqueda de soluciones colectivas a través de movimientos sociales (coyuntura de corto plazo).

La pregunta que se plantea es si los jóvenes serán capaces de recoger el legado histórico de sus pares de otras épocas (y de otros lugares del mundo) y podrán conquistar cuotas de poder que les permitan promover los cambios que esperan y por los cuales luchan.

El esperado cambio de la sociedad está institucionalizado a través del sistema de elecciones, pero como ya hemos visto, en este sistema la mayoría de jóvenes no participa (Theza, 2010) y esa no participación es diferenciada según estrato socioeconómico, los jóvenes más pobres 
participan menos y no votan, en cambio los jóvenes más ricos participan más y votan por la derecha, sin embargo son la minoría. La mayoría de los jóvenes de clase media, media-baja y baja no creen en esta democracia representativa. Esto se ve reflejado en la siguiente aseveración: «para que exista una real y verdadera democracia las personas deben confiar entre ellas» y eso no está sucediendo en nuestro país.

La mayoría de los jóvenes consultados en nuestra investigación afirman categóricamente que «en Chile actualmente no existe una democracia plena», que «se impone la ley de la selva» y «para que exista una real y verdadera democracia es indispensable que las personas confíen en las instituciones» y los datos presentados con anterioridad le dan toda la razón a las percepciones juveniles.

En este contexto, Mayol (2011) plantea que «la única obra humana positiva (en Chile) eran las instituciones. Con esa base era posible que el país no estuviera de acuerdo con las políticas aplicadas y al tiempo las aceptara con complacencia», y que al mismo tiempo los chilenos siempre estuvieron en desacuerdo con el modelo. A este tipo de actores sociales Mayol los conceptualiza como «los rebeldes adaptativos». Sin embargo, dada la coyuntura mundial que se visibilizó desde España a partir de mayo del 2011, los «rebeldes adaptativos» chilenos se dejaron de adaptar y encontraron en las redes sociales un lugar nuevo para configurar el espacio público; la consecuencia de este fenómeno sería el derrumbe de las instituciones en Chile. El caso más impactante de este derrumbe estaría dado por la Iglesia Católica chilena, la que ha descendido en la escala de confianza social de un 80\% en 1995 a solo un 38\% en el año 2011 (Latinobarómetro, 2011).

De esta manera la vivencia juvenil en una sociedad de mayor complejidad (Morin, 2003), más líquida (Bauman, 2006) y de riesgo (Beck, 2003), exige a los jóvenes construir por sus propios medios y fuerzas un sentido de futuro. Esta situación genera mayor individualismo y desconfianza en los otros, fragmentando la cohesión social.

Desde esta perspectiva, el imaginario social que existe entre los jóvenes sobre la cohesión social es vacuo, dado que la noción de sociedad que introyectaron durante estos años - esa visión que contenía promesas fundamentales como justicia social, igualdad - no fue cumplida, lo que conduce a una sociedad vacía (Lipovetsky, 1983), sin proyecto, sin futuro, una sociedad que no los incluye y que cuando manifiestan su descontento en las calles, son reprimidos, estigmatizados, criminalizados y rotulados como «inútiles y subversivos». 
A pesar de las movilizaciones juveniles lo que pasa de fondo actualmente en Chile no permite pensar en la posibilidad de una sociedad unida, sin diferencias sociales, en torno a objetivos comunes; la tendencia generalizada es a solucionar los problemas individualmente, sin articular causas colectivas. Para lograrlo habría que encontrar causas comunes que unan a todos los chilenos. Es por eso que las movilizaciones juveniles del 2011 abren la inquietud y reflexión sociológica.

Cuando a los jóvenes participantes en la investigación se les consultó «¿qué une a los chilenos?», la respuesta fue unánime y contundente: «la Teletón» y la «roja de todos» (selección nacional de fútbol), ambos son fenómenos mediáticos pasajeros, sin embargo, tienen un tremendo poder de manipulación de las conciencias individuales. Todos se sienten «uno» cuando prenden el televisor y la selección nacional de fútbol está jugando o cuando «Don Francisco», ${ }^{1}$ grita con algarabía que «hemos cumplido la meta».

Pero este «uno» se desvanece en el aire con la misma rapidez con la que los chilenos apagan el televisor, es una «unidad» entre comillas, es un «cemento» artificial que nos une por algunos instantes, pero al terminar el show nos deja vacíos como antes de ver el espectáculo.

\section{c) Confianza y democracia}

Como señalábamos anteriormente, la falta de confianza entre las personas, y sobre todo en las instituciones, lesiona gravemente la democracia en el país, se requiere de ese lazo invisible y fundamental para que la sociedad se constituya como tal, para no ceder a la definición de Margaret Thatcher que en la década del 80 nos decía que la sociedad no era más que la suma de individuos.

En ese proceso de constitución social, los jóvenes perciben que la política desune a los chilenos, que al revés de lo esperado, el quehacer de los políticos chilenos lo único que logra es generar más desconfianza; «ellos trabajan para ellos mismos, no para el pueblo», nos señalan los jóvenes entrevistados. La visión juvenil generalizada es que los políticos son «ineficientes y corruptos»; por lo tanto, no constitu-

1 Mario Kreutzberger más conocido como «Don Francisco», es un animador de televisión que lleva más de treinta años en pantalla animando un popular programa llamado «Sábados Gigantes» y hace más de veinticinco años animando la «Teletón», programa televisivo destinado a reunir dinero para la rehabilitación de personas con discapacidad física. 
yen un referente a imitar o emular, muy por el contrario, son vistos con recelo, con distancia, con desconfianza.

\section{d) La participación social y sus efectos en la confianza juvenil}

Un dato empírico interesante aparecido en la investigación es que los jóvenes que participan en organizaciones sociales poseen un mayor nivel de confianza en los otros, en comparación con quienes no participan; lo anterior quedó demostrado en los relatos juveniles analizados; pareciera ser que el hecho de estar con otros, de realizar actividades en conjunto contribuye a generar lazos de confianza; lo lamentable es que en general esta participación social es baja. Son pocos los jóvenes que participan de manera estable en algún tipo de organización social.

Al mismo tiempo los jóvenes nos señalan que las personas más seguras de sí mismas confían más en los otros; ellos tienen una postura más abierta al diálogo y a la comunicación interpersonal. Lo que concuerda con Roger (1979).

Existe consenso entre los jóvenes estudiados en señalar que aquellos que han participado en organizaciones sociales —o que participan actualmente - tienden a confiar más en los demás; son jóvenes con historias colectivas ricas en intercambios; este tipo de jóvenes son más sociables, solidarios y comprometidos con el país. Por su parte, los estudiantes que participan más en sus organizaciones confían más en los otros; en este sentido la socialización secundaria (Dubet, 1996) que experimentan los jóvenes en su vida estudiantil les facilita relacionarse con los demás; en este proceso es fundamental el desarrollo de una convivencia escolar sana, tranquila, segurizante. Para ello el rol de los profesores es clave (Cassasus, 2003) al momento de generar un ambiente de aula gratificante y que traerá como consecuencia positiva un mejor rendimiento escolar.

Investigadores como Maturana (2004), Casassus (2003) y Naranjo (2007) plantean que en el marco de la función propiamente educativa o formativa de la institución escolar, se instalan nuevos desafíos vinculados a la humanización y formación valórica de los jóvenes. Estos nuevos desafíos se constituyen en funciones educativas emergentes que tensionan la escuela en el contexto de los actuales cambios que vive el conjunto de la sociedad, y que como tal desbordan la función meramente productora del proceso de escolarización.

Los estudiantes que poseen menor experiencia de contacto con otros diversos a ellos en cuanto nivel socioeconómico (por la segmen- 
tación del sistema escolar) tienden más a desconfiar de los demás, mientras que los jóvenes que se relacionan frecuentemente con otros distintos a ellos son más tolerantes y confían más en los otros.

Los jóvenes que en su experiencia escolar han vivenciado una mayor confianza en sus personas, han tenido mayor posibilidad de protagonismo en sus establecimientos escolares, desarrollan estas certezas básicas que los acompañan en su vida cotidiana; estas certezas se forman en la familia y en la escuela, por lo tanto, los procesos de socialización primaria y secundaria son fundamentales (Dubet, 1996). Al respecto, el autor señalado plantea lo siguiente:

En una primera instancia, la experiencia es una manera de vivenciar, de ser invadido por un estado emocional suficientemente fuerte para que el actor no se pertenezca verdaderamente al descubrir su subjetividad personal. Es por eso que se habla habitualmente de experiencia estética, amorosa o religiosa. Pero esta representación de «lo vivido» es por naturaleza ambivalente. Por una parte, aparece como propiamente individual...manifestación romántica del «ser» único y de su historia particular. Por otra parte, la experiencia puede concebirse como la superposición de la sociedad y de la «conciencia individual», como ese «trance» original de lo social del que hablaban Durkheim y Weber, en el que el individuo olvida su Yo para fundirse en una emoción común, la del «gran ser» que no es otra cosa que la sociedad percibida como una emoción... A esta representación emocional de la experiencia se yuxtapone un segundo significado: la experiencia es una actividad cognitiva, una manera de construir lo real y sobre todo de «verificarlo», de vivenciarlo. La experiencia construye fenómenos a partir de las categorías del entendimiento y de la razón. Evidentemente para el sociólogo, estas categorías son, en primer lugar, sociales; son «formas» de construcción de la realidad. Desde este punto de vista, la experiencia social no es una «esponja», una manera de incorporar el mundo a través de las emociones y sensaciones, sino una manera de construir el mundo (Dubet, 1994:92-94).

\section{e) Hitos en la construcción/deconstrucción de confianza}

i. En relación a las personas

La investigación que estamos realizando nos permite concluir que la confianza en las personas no es espontánea, se requiere un largo proceso para llegar a confiar en alguien y está directamente relacionada con la lealtad y fidelidad de las personas entre sí. Se pierde la confianza en alguien si uno se siente traicionado; en ese sentido es mucho 
más difícil llegar a confiar en alguien, que perder la confianza en una persona.

Cuando se pierde la confianza en alguna persona es imposible restaurar las relaciones personales, «es como un vidrio que se quebró» nos dijeron varios jóvenes; jamás volverá a ser como era antes. Si una persona confía en otra y le cuenta sus secretos y posteriormente esa persona los divulga a otros implica perder la confianza definitivamente en ella o en él, por lo tanto, no se puede volver a confiar en alguien que ha traicionado la confianza de uno, al mismo tiempo se puede desconfiar de alguien sin conocerlo (es un rechazo a primera vista) y no es necesario haber confiado en alguien para después desconfiar de él o ella.

Los datos que nos entrega la VI Encuesta Nacional de Juventud (INJUV, 2009) nos señalan lo siguiente:

\section{CUADRO 2: CONFIANZA EN LAS PERSONAS}

\begin{tabular}{|c|c|}
\hline Familiares & $81,5 \%$ \\
\hline Amigos & $68,2 \%$ \\
\hline Compañeros de curso & $39,0 \%$ \\
\hline Profesores & $32,4 \%$ \\
\hline Carabineros & $29,5 \%$ \\
\hline Presidente de la República & $19,5 \%$ \\
\hline Sacerdotes & $18,3 \%$ \\
\hline Líderes juveniles & $15,5 \%$ \\
\hline Jueces & $11,5 \%$ \\
\hline Alcaldes & $6,7 \%$ \\
\hline Políticos & $2,8 \%$ \\
\hline Senadores & $2,7 \%$ \\
\hline
\end{tabular}

Fuente: VI Encuesta Nacional de Juventud, INJUV, 2009.

Por su parte, la II Encuesta sobre Valores en los jóvenes que hemos realizado en el Centro de Estudios en Juventud (CEJU), de la Universidad Católica Silva Henríquez nos señala lo siguiente:

\section{CUADRO 3: CONFIANZA EN LOS DEMÁS}

\begin{tabular}{|c|c|}
\hline Se puede confiar en la mayoría de la gente & $4,1 \%$ \\
\hline Nunca se sabe las intenciones de los otros & $84,2 \%$ \\
\hline Es mejor no confiar en nadie & $11,8 \%$ \\
\hline
\end{tabular}

Fuente: II Encuesta sobre Valores, CEJU, 2009. 
Como podemos constatar en ambos estudios hay coincidencia en el sentido que los espacios privados otorgan mayor seguridad y confianza en los jóvenes, en cambio todo lo referido a lo público genera desconfianza, es por eso que ellos nos señalan que «nunca se sabe las intenciones de los otros», por eso es mejor estar alerta y andar con cuidado; o como dicen los adultos: «en la confianza está el peligro».

ii. En relación a las instituciones

La gran mayoría de los jóvenes actuales no confía en las instituciones (Encuesta Nacional de Juventud, 2009); las organizaciones políticas son las que menos confianza les merecen.

CUADRO 4: CONFIANZA EN LAS INSTITUCIONES

\begin{tabular}{|c|c|}
\hline INSTITUCIONES & GRADO DE CONFIANZA \\
\hline Universidades & $38,8 \%$ \\
\hline Escuelas/Liceos & $31,0 \%$ \\
\hline Carabineros & $27,4 \%$ \\
\hline Iglesia Católica & $24,6 \%$ \\
\hline Medios de comunicación & $21,1 \%$ \\
\hline Poder Judicial & $10,3 \%$ \\
\hline Municipalidades & $9,9 \%$ \\
\hline Congreso de la República & $2,5 \%$ \\
\hline Partidos Políticos & $2,2 \%$ \\
\hline
\end{tabular}

Fuente: VI Encuesta Nacional de Juventud, INJUV, 2009.

En este contexto es la Iglesia Católica y especialmente los sacerdotes quienes más han ido perdiendo la confianza entre los jóvenes debido, entre otros, a los frecuentes casos de pedofilia dados a conocer a través de los medios de comunicación.

Según la Encuesta Nacional 2011 de la Universidad Diego Portales «los escándalos por abusos sexuales de personeros de la Iglesia Católica han afectado en forma importante la confianza social en dicha institución, en 2010 el 42,9\% tenía bastante o mucha confianza en esta institución, mientras que el año 2011 sólo se alcanzó el 24,1\%» (UDP, 2011).

La misma encuesta señala que el 52,2\% considera que la Iglesia Católica ha intentado ocultar el tema sobre abusos sexuales. Solo $12 \%$ sostiene que ha intentado esclarecerlo. $48,5 \%$ de quienes se declaran católicos piensa que la iglesia ha intentado ocultar los casos de abusos 
sexuales a niños, niñas y adolescentes. El 38,3\% de los practicantes católicos - por lo menos una vez al mes asisten a la iglesia- creen que la Iglesia Católica ha intentado ocultar el tema. La cifra se eleva al $54 \%$ en los católicos que son menos practicantes (asisten dos o tres veces al año a la iglesia/o nunca) (UDP, 2011).

El $44,8 \%$ de las personas considera que los abusos sexuales de sacerdotes se mantendrán a futuro y el $21,5 \%$ indica que los abusos aumentarán. El 65\% considera que los abusos sexuales de sacerdotes a niños, niñas y adolescentes son prácticas recurrentes. El 59,9\% de los católicos consideran que son prácticas recurrentes, mientras los que se identifican con otras religiones creen lo mismo en un 69,3\% (UDP, 2011).

La única institución que merece la confianza de los jóvenes es el Cuerpo de Bomberos dado que son voluntarios; respecto de todas las demás instituciones (públicas y privadas), los jóvenes marcan una distancia con ellas y prefieren realizar sus actividades fuera del mundo institucional, ya que a decir de ellos «las instituciones chilenas trabajan sólo por sus propios intereses», incluso aquellas que piden donaciones en los supermercados, «nunca nadie sabe qué se hace con esa plata» nos dijeron varios entrevistados. En especial los jóvenes consideran que los políticos son sinverguienzas, que se aprovechan de la gente, sobre todo en época de campañas, porque están requiriendo un voto; «los políticos dicen una cosa y hacen otra», por eso los jóvenes no confían en ellos.

\section{f) Acerca de la competencia en Chile}

Más allá de las teorías que nos hablan de las bondades o maldades de la competencia, sobre todo fuera del ámbito económico, el relato juvenil analizado nos afirma que en Chile «las personas viven compitiendo». Al mismo tiempo los jóvenes nos señalan que «la competencia daña las relaciones humanas»; no permite la sana cooperación y solidaridad entre pares; en ese sentido es fundamental regular la competencia, generar mecanismos de control social que sean respetados y que permitan generar los equilibrios necesarios para una sana convivencia social, ya que la competencia sin regulación daña a las personas, fomenta el individualismo y en ese duro juego social siempre pierden los más pobres.

Los jóvenes en sus entrevistas nos señalaron reiteradamente que en nuestro país «cada uno vela por sí mismo», sin preocuparse de los demás lo que resta posibilidad de articular proyectos colectivos en los 
cuales creer y entusiasmarse. En una sociedad con esas características, el futuro juvenil es incierto, cualquiera sea su condición socioeconómica; nada asegura que los estudios que están realizando les van a permitir una adecuada inserción laboral; hay un evidente desfase entre educación y trabajo.

Hace ya un par de décadas que el país está siendo gobernado con criterios empresariales, más aún en la coyuntura del actual gobierno. El sentir juvenil nos señala que Chile está gobernado por empresarios y gerentes, a los que en verdad no les interesa la gente, sobre todo los más pobres. Muchos jóvenes consideran que en Chile el «Estado fue comprado por los empresarios», al respecto cabe señalar que en muchas murallas europeas se puede ver escrita actualmente la siguiente consigna juvenil: «no confíes en el E\$tado».

En ese sentido, la percepción juvenil nos señala que «Chile es un país donde reina el mercado», todo tiene un precio; más aún, a la gente le gusta el mercado y el consumo es utilizado como un mecanismo de integración social; sin embargo, no todos pueden participar de los beneficios del sistema económico de la misma forma, siendo los pobres los eternamente desfavorecidos; «vulnerables» se dice actualmente.

En ese contexto, los jóvenes consideran que el Estado debería estar más presente en la vida de los chilenos, que la salud y la educación deberían ser responsabilidad del Estado y no dejarlas sujetas solo a las reglas de mercado; lo anterior está a la base de las movilizaciones estudiantiles del 2011.

\section{CONCLUSIONES}

A partir del estudio que estamos realizando hemos llegado a la conclusión que en el mundo juvenil chileno contemporáneo existe una tensión muy fuerte entre un relativismo generalizado. Es decir, que las conductas juveniles se organizan en base a la capacidad de ver, pensar $\mathrm{y}$ actuar en un contexto de descomposición de un mundo moderno y su moral universal, junto a la emergencia de la fragmentación del otro, de pluralidad de lógicas de acción (Dubet, 1994) de éticas yuxtapuestas; y el intento de constituirse en actores sociales relevantes, a través de un movimiento juvenil fuerte, propositivo, con poder; estos serían los «indignados chilenos».

Los jóvenes chilenos actuales viven en la compleja transición (Morin, 2003) de un mundo que se termina y otro que emerge con fuerza inusitada; es la emergencia de un nuevo modelo cultural (Bajoit, 1996) 
que se instala en las vidas juveniles y que articula sus proyectos de vida. En este devenir sociopolítico, algunos jóvenes están interpelando a la sociedad chilena en su conjunto, mientras que otros están luchando por sí mismos para sobrevivir material y simbólicamente.

Como bien lo señalara Weber (1996), los seres humanos organizan sus conductas en base a la ética de la responsabilidad o a la ética de la convicción, sin embargo la constatación empírica reiterada en el mundo juvenil nos permite afirmar que la ética que se impone en el mundo juvenil chileno actual es la ética situacional, la que según Maffesoli (2007), es la ética propia de las «diversas tribus postmodernas». Este autor señala que estamos ante la emergencia de una época donde la búsqueda, moral, de salvación, en su aspecto cuantitativo, tiende a dejar lugar a una relación cualitativa de relativismo permanente.

En el Chile contemporáneo este tipo de ética se incuba en las llamadas tribus urbanas postmodernas, donde la intensidad de sus acciones y la violencia de sus pasiones se ve reflejada en el fanatismo musical, en la adicción a las redes informáticas (facebook y twitter) y en la «adhesión intensa y provisoria a causas humanitarias o caritativas» (Maffesoli, 2007).

En esta lucha juvenil, material y simbólica, es imposible hacer prognosis certeras; lo más prudente en términos intelectuales es plantear algunas hipótesis que deben ser comprobadas empíricamente; éstas son las siguientes:

- La actual generación de jóvenes chilenos carece de una socialización política consistente lo cual le dificulta distinguir entre intereses y problemas estructurales de causas coyunturales, centrando sus energías, de manera pasajera, en luchas coyunturales, sin proyección en el tiempo.

— La tensión que se advierte entre la resolución de problemas de manera individual y la constitución de un movimiento social juvenil que logre soluciones colectivas serán resueltas a corto plazo por el repliegue juvenil en espacios privados.

- Los jóvenes más pobres no esperan nada de la democracia, por lo tanto, buscan su integración a través del consumo, a pesar de sus dificultades económicas.

- La desconfianza juvenil en las instituciones impide la configuración de causas colectivas y contribuye a la desintegración social.

- En la medida que se mantengan los altos niveles de desconfianza de los jóvenes hacia las instituciones y hacia el mundo adulto, la cohesión social en Chile se verá dificultada. 
— El repliegue individual juvenil sobre el mundo privado favorece el statu quo.

- Los jóvenes indignados chilenos serán cooptados por las lógicas institucionales (educación y trabajo), a pesar de las movilizaciones sociales que han protagonizado.

- A pesar de la entrada en vigencia de la nueva ley de inscripción automática y voto voluntario, los jóvenes chilenos, mayoritariamente, manifestarán su rechazo al sistema económico y político absteniéndose de votar.

- Las manifestaciones juveniles estudiantiles se mantendrán por un tiempo, sin embargo, la presión de sus familiares y adultos significativos los obligarán a reintegrarse al sistema como clientes/consumidores (estudiantes y trabajadores).

- La ciudadanía juvenil actual tendrá una corta duración dados los mecanismos de mercado dominantes en la sociedad chilena.

- La desconfianza de los jóvenes permanecerá sin mayores cambios, permitiendo que el establishment político y económico permanezca intacto.

- Dado que los jóvenes sólo tienen legitimidad, pero no poder, los sectores socioeconómicos dominantes mantendrán sus privilegios, sin alterar el statu quo, ni generar cambios estructurales.

SANTIAGO (CHILE), FEBRERO 2012

RECIBIDO, FEBRERO 2012

ACEPTADO, ABRIL 2012 


\section{REFERENCIAS BIBLIOGRAFICAS}

BAJOIT, GUY (2003): Todo cambia. Análisis sociológico del cambio social y cultural en las sociedades contemporáneas. Santiago: Lom Ediciones.

— y ABRAHAM FRANSSEN (1995): Les Jeunes dans la Compétition Culturelle. Sociologie D'aujourd'hui. Louvain-la-Neuve: PUF.

BAUMAN, ZYGMUNT (2007): Los retos de la educación en la modernidad líquida. Barcelona: Editorial Gedisa.

— (2006): Vida líquida. Buenos Aires: Editorial Paidós.

- (1999): La globalización. Consecuencias humanas. Buenos Aires: FCE.

BECK, UlRICH (2008): World at Risk. Cambridge: Polity Press.

- (2000): Qué es la globalización. Falacias del globalismo, respuestas a la globalización. Barcelona: Editorial Paidós.

BRUNNER, JOSÉ JOAQUíN (1998): Globalización cultural y postmodernidad. Santiago: FCE.

CASSASUS, JuAn (2003): La escuela y la (des)igualdad. Santiago: Lom Ediciones.

DUBET, FRANÇOIS (2004): L'école des chances: Qu'est-ce qu'une école juste? Paris: Seuil.

— (2002): Le déclin de l'institution. Paris: Seuil. (1996): En la escuela. Sociología de la experiencia escolar. Madrid: Editorial Losada. (1994): Sociologie de l'expérience. La couleur des idées. Paris: Seuil.

CENTRO DE INVESTIGACIÓN EN ESTRUCTURA SOCIAL (CIES) (2009): «Encuesta metropolitana». Santiago: Universidad de Chile.

FUKUYAMA, FRANCIS (1996): Confianza. Buenos Aires: Editorial Atlántida.

GIDDENS, ANTHONY (1994): Consecuencias de la modernidad. Madrid: Editorial Alianza.

HESSEL, STÉPHANE (2010): Indignez-Vous. Essay. Indigène. Montpellier.

HOPENHAYN, MARTÍN (2007): «Cohesión social: una perspectiva en proceso de elaboración». En ANA SOJO y ANDRAS UTHOFF (editores): Cohesión social en América Latina y el Caribe: una revisión perentoria de algunas de sus dimensiones. Santiago: CEPAL.

InSTITUTO NACIONAL DE LA JUVENTUd (2009): Sexta encuesta nacional de juventud. Santiago: INJUV.

JIRÓN, MARCELA et al. (2008): "Consumo de antidepresivos en Chile entre 1992 y 2004». Revista Médica de Chile. Santiago.

LATINOBORÓMETRO (2010): «Opinión pública latinoamericana».

LIPOVETSKY, GILLES (1983): La era del vacío. Barcelona: Anagrama.

MAFFESOLI, MiCHEL (2007): Le réenchantement du monde. Un étique pour notre temps. Paris: La Table Ronde.

MARTUCCELLI, DANILO (2007): Cambio de rumbo. La sociedad a escala del individuo. Santiago: Lom Ediciones. 
MAturana, Humberto et al. (2004): Del ser al hacer, los orígenes de la biología del conocer. Santiago: Lom Ediciones.

MAYOL, ALBERTO (2011): «Ponencia en la ENADE». Santiago.

MORIN, EDGAR (2005): Introduction à la pensée complexe. Paris: Éditions du Senil.

NARANJO, ClAUDIO (2007): Cambiar la educación para cambiar el mundo. Santiago: Editorial Indigo-Cuarto Propio.

PNUD (2009): Desarrollo humano en Chile. La manera de hacer las cosas. Santiago: PNUD.

ROGERS, KARL (1979): El proceso de convertirse en persona. Buenos Aires: Editorial Paidós.

SADER, EMIR (2009): El nuevo topo. Los caminos de la izquierda latinoamericana. Buenos Aires: Siglo XXI y CLACSO.

SERVEL (2012): «Servicio Electoral de Chile». Santiago.

VAtTimo, Gianni (1998): La sociedad transparente. Barcelona: Paidós.

UNIVERSIDAD DIEGO PORTALES (2011): «Encuesta nacional». Santiago: UDP.

THEZA, MARCEL (2010): «Les écueils pour l'exercise de la citoyenneté électorale des jeunes des milieux pauvres au Chili». Faculté des Sciences Économiques, Sociales, Politiques et de Comunication. Université Catholique de Louvain. Louvain-la-Neuve: Presse Universitaires de Louvain.

Touraine, Alain (2006): Un nuevo paradigma. Para comprender el mundo de hoy. Buenos Aires: Editorial Paidós.

WeBER, MAX (1996): Economía y sociedad. Ciudad de México: FCE.

ZENNET, RICHARD (2006): La corrosión del carácter: las consecuencias personales del trabajo en el nuevo capitalismo. Barcelona: Anagrama. 